Paper published by the Structural Concrete Laboratory of EPFL

\begin{tabular}{|l|l|}
\hline Title: & Design for punching of prestressed concrete slabs \\
\hline Authors: & Clément T., Ramos A.P., Fernández Ruiz M., Muttoni A. \\
\hline Published in: & Structural Concrete \\
\hline DOI & $10.1002 /$ suco.201200028 \\
\hline City, country: & Lausanne, Switzerland \\
\hline Year of publication: & 2012 \\
\hline Type of publication: & Peer reviewed journal article \\
\hline
\end{tabular}

Please quote as:

Clément T., Ramos A.P., Fernández Ruiz M., Muttoni A., Design for punching of prestressed concrete slabs, Structural Concrete, Lausanne, Switzerland, 2012. 


\section{DESIGN FOR PUNCHING OF PRESTRESSED CONCRETE SLABS}

Thibault Clément, António Pinho Ramos, Miguel Fernández Ruiz and Aurelio Muttoni

\section{ABSTRACT}

Prestressing in flat slabs helps in controlling deformations and cracking under service loads and allows reducing the required slab thickness, leading thus to more slender structures and being therefore an economic solution for long spans. However, as a consequence of the limited thickness of these members, punching is typically governing at ultimate limit state. Investigations on the topic of punching shear strength have shown that the presence of prestress in flat slabs has a number of potential beneficial effects, namely the vertical component (force) carried by inclined tendons, the in-plane compression stresses and the bending moments developed near the supported region. The approach provided by codes of practice for punching design in presence of prestressing may however differ significantly. Some neglect the influence of the introduced bending moments due to prestressing and the sections at which deviation forces of the tendons are considered may be located at different distances from the edge of the supported region. In this paper, the influence of prestressing on the punching shear strength of members without shear reinforcement is investigated by using the fundamentals of the Critical Shear Crack Theory. On that basis, and accounting also for 65 tests available in the scientific literature, the suitability and accuracy of a number of design codes, such as Model Code 2010, Eurocode 2 and ACI 318-11, is investigated and compared. typesetting, pagination and proofreading process, which may lead to differences between this version and the Version of Record. Please cite this article as doi: 10.1002/suco.201200028. 
Keywords: punching, flat slabs, slab bridges, prestressing, in-plane forces, code predictions, Model Code 2010

\section{INTRODUCTION}

Prestressed flat slabs are extensively used in Europe for small and medium span bridges. They are also a common solution for foundations mats and long span flat slabs in buildings (for spans larger than 10-12 m) as shown in Figure 1. Although simple in appearance, a flat slab system presents a complex load bearing behaviour, especially at slab-column connections where punching resistance is frequently the governing design criterion. Punching failure results from the interaction of shear forces and bending moments near the supported areas, and is typically characterised by brittle failures (particularly associated to large depth and/or large flexural reinforcement ratios). Although punching failure is local (developing at a single slab-column connection), it overloads adjacent columns and can lead to progressive collapses [3]. In recent years, there had been some examples of progressive collapses of this type of structures that originated important material and human losses (see [6,12]).

With respect to the influence of prestressing on the punching shear strength, it has been reported a number of potential beneficial effects on the literature $[22,23]$ :

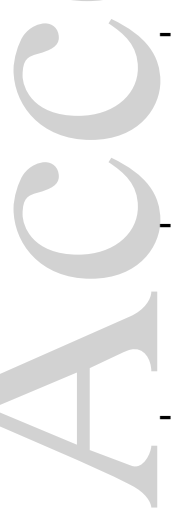

the vertical component resulting from inclined tendons near the column (direct transmission of the shear force to the support),

the presence of compression stresses in the concrete resulting from prestressing, which have been reported to lead to an increase on the punching shear,

- the moments due to the prestressing eccentricity, that in general have opposite sign to those of from gravity loads and, in this case, have also been reported to increase the punching shear strength. 
The present work investigates the influence of prestressing on the punching shear strength of flat slabs. To that aim, the Critical Shear Crack Theory is used. This theory provides a mechanical model suitable for investigating shear and punching shear problems and was selected as the state-of-the-art model to ground fib Model Code 2010 (MC2010 [4]) punching shear provisions. The results of this theory, following the MC2010 implementation, as well as other codes based on empirical formulations for punching shear design (such as Eurocode 2 [2] or ACI318-11[1]) are compared to a set of 65 tests available in the scientific literature drawing a number of conclusions on the pertinence and accuracy of each approach.

\section{INFLUENCE OF PRESTRESSING ON THE PUNCHING SHEAR OF CONCRETE}

\section{SLABS}

As previously stated, prestressing induces a number of phenomena influencing punching shear strength. In the following, these phenomena will be investigated on the basis of the Critical Shear Crack Theory (CSCT). A detailed description of the fundamentals of this theory and of its implementation on MC2010 has been presented elsewhere [14].

According to the CSCT, the punching shear strength $\left(V_{R}\right)$ depends on the opening $(w)$ and roughness of a critical shear crack developing through the compression strut carrying shear,

Figure 2a. Assuming the opening of the critical shear crack to be proportional to the product of the slab rotation times the effective depth of the slab $(w \propto \psi \cdot d)$, and that the roughness of the crack is correlated to the maximum size of the aggregates $\left(d_{g}\right)$, the following failure criterion was proposed by Muttoni for average values [11,14] (Figure 2b, refer to average failure criterion):

$\frac{V_{R}}{b_{0} \cdot d_{v} \sqrt{f_{c}}}=\frac{3 / 4}{1+15 \frac{\psi \cdot d}{d_{g}+d_{g 0}}}$ 
Where $f_{c}$ refers to the compressive strength on concrete measured on cylinder, $d$ to the effective depth of the member, $d_{v}$ to the shear-resisting effective depth (accounting for supported area penetration [14]), $b_{0}$ to a control perimeter located at $d_{v} / 2$ from the face of the supported area and $d_{g 0}$ is a reference aggregate size (equal to $16 \mathrm{~mm}$ ).

On the basis of this criterion, and accounting for characteristic material properties and safety factors, the following design failure criterion $\left(V_{R d}\right)$ was proposed [11] and recently adopted by MC2010 [14] (Figure 2b, refer to characteristic failure criterion with $\gamma_{c}=1.0$ ):

$$
\frac{V_{R d}}{b_{0} \cdot d_{v} \frac{\sqrt{f_{c k}}}{\gamma_{c}}}=\frac{1}{1.5+0.9 \cdot \psi \cdot d \cdot k_{d g}} \leq 0.6
$$

Where $f_{c k}$ refers to the characteristic compressive strength of concrete measured on cylinder, $\gamma_{c}$ is the partial safety factor for concrete (typically equal to 1.5 ) and $k_{d g}$ is a coefficient accounting for the maximum aggregate size whose value can be calculated as:

$$
k_{d g}=32[\mathrm{~mm}] /\left(16+d_{g}\right) \geq 0.75
$$

Calculation of a failure load can thus be performed by intersecting the actual behaviour of a slab (characterized by its load-rotation behaviour) with the failure criterion (Figure 2c).

For design of prestressed slabs, the influence of the prestressing has to be accounted on the actions and actual behaviour of the slab. With respect to the shear transferred by concrete $\left(V_{c}\right)$, it can be noted that it is reduced by the inclined component (force) of the tendons (refer to Figure 3a):

$$
V_{c}=R-\int_{A} q \cdot d A-V_{P}=V_{E}-V_{P}
$$

Where $R$ refers to the reaction on the supported area, $q$ to the external loads acting on top of the punching cone, $V_{E}$ to the acting shear force (difference of the previous components) and $V_{P}$ to the inclined force carried by the tendons intercepted by the punching surface (alternatively, accounting the deviation forces of prestressing on term $q$ and considering $V_{P}=0$ 
yields the same results). It can be noted that punching failure occurs when the shear transferred by concrete $\left(V_{c}=V_{E}-V_{P}\right.$, Eq. (4)) equals the available concrete strength $\left(V_{R}\right.$, Eqs.

$(1,2))$.

With respect to the influence of prestressing on the behaviour of the slab which is governed by the rotation of the slab $(\psi)$, two different phenomena can be observed. The first one relates to the influence of compression normal stresses acting on the slab (Figure 3b) which delay concrete cracking and stiffen the cracked response of concrete. This leads to stiffer loadrotation behaviours than for non-prestressed slabs for the same amount of flexural reinforcement and increases thus the punching shear strength, refer to point B on Figure 3b. It can be noted that for tensile normal stresses (which should not be the case of prestressing), this effect will lead to a softer response and thus to lower punching shear strength (point $\mathrm{C}$ on Figure $3 b)$. The second phenomenon on the load-rotation response refers to the eccentricity of the tendons which originate bending moments on the failure region. These moments, when they oppose to those of the external actions, also delay cracking of the concrete and stiffen the overall response of the member (refer to point B' on Figure $3 \mathrm{c}$ where, as sign convention, positive moments lead to tension on the top side of the slab). This is the case for typical arrangements of prestressing tendons. In case the moments are of same sign as those of the external actions, a reduction on the punching shear strength will however follow (softer loadrotation behaviour, refer to point $C^{\prime}$ in Figure $3 \mathrm{c}$ )

These observations on the influence of in-plane forces and bending moments on the punching shear strength were already noted by the Fip Recommendations for the Design of PostTensioned Slabs and Foundations [20] and other authors [8,22,23] who proposed to use the decompression moment as a suitable parameter to account for the combined influence of moments and normal forces. This is also the approach followed by the CSCT and that has been implemented on MC2010 as it will later be explained. 
With respect to the influence of prestressing on the failure criterion, it can potentially influence the shear transfer capacity of concrete in a positive manner (increase of the compression zone carrying shear). For design purposes, however, this influence is usually neglected. This is for instance the approach followed by MC2010, which nevertheless (and as later shown in the paper) leads to sufficiently accurate and safe results when compared to test results.

\section{DESIGN FOR PUNCHING IN PRESTRESSED SLABS}

A number of design codes and recommendations are available for punching shear design of prestressed concrete flat slabs. They however present significant differences in their nature (empirical formulations or physical models) and on the treatment of the prestressing effects and their evaluation. In the following two empirical approaches (Eurocode 2 and ACI 31811), as well as MC2010 (based on the physical model of the CSCT) will be examined in detail and compared to test results.

\section{Eurocode 2 (2004)}

The punching shear strength for Eurocode 2 is expressed in Eq. (5). It can be noticed that the vertical component of tendons $V_{p, E C}$ (see Figure 4) is calculated at $2 d$ from the border of the column and is taken into account as an action.

$V_{E}-V_{p, E C} \leq V_{R, E C}=\left[0.18 \cdot k \cdot\left(100 \cdot \rho \cdot f_{c}\right)^{1 / 3}+0.1 \cdot \sigma_{c}\right] b_{E C} \cdot d$

where:

$k=1+\sqrt{\frac{200}{d}} \leq 2 d$ being in [mm](size effect factor, to be noted that no limit is considered by some authors $[22,23]$ ) 


$$
\rho=\sqrt{\rho_{l x} \cdot \rho_{l y}} \leq 0.02
$$

$b_{E C}$ is the control perimeter located at $2 d$ from the border of the column (Figure 4).

This expression accounts for the presence of normal stresses but not for the eccentricity of the tendons (moments).

\section{ACI 318 (2011)}

The punching strength prediction is expressed according to Eq. (6), which takes into account the vertical component of the tendons $V_{p, A C I}$, calculated at $0.5 d$ from the border of the column as an additional strength, contrary to Eurocode 2 .

$$
V_{E} \leq V_{R, A C I}=\left[\beta_{p} \cdot \sqrt{f_{c}}+0.3 \cdot \sigma_{c}\right] b_{A C I} \cdot d+V_{p, A C I}
$$

where:

$$
\beta_{p}=\min \left(3.5 ; \frac{40 d}{b_{A C I}}+1.5\right)
$$

$b_{A C I}$ is the control perimeter located at $0.5 d$ from the border of the column (Figure 4)

As for Eurocode 2, this expression accounts for normal stresses but not for eccentricity of the tendons. Contrary to Eurocode 2, no size effect factor is accounted.

\section{Model Code 2010}

MC2010 [4] incorporates a number of significant changes with respect to previous versions of Model Code (1978, 1990), refer to [14]. This is particularly relevant for shear and punching shear design for members without transverse reinforcement, where instead of previous empirical formulations, design is based on consistent physical theories. For punching shear, the provisions are grounded on the physical model of the CSCT. Another significant innovation in Model Code 2010 with respect to other codes is that it proposes to 
perform design based on the Levels-of-Approximation (LoA) approach, see [13,14]. Such an approach consists on improving the accuracy on the estimate of the strength and behaviour of a member by successive refinements on the value of the physical parameters accounted by the design model. This allows performing simple and low time-consuming estimates of the strength for preliminary design (LoA I) and more refined ones (LoA II and following) for tender or executive design as well as for assessment of existing critical structures. Hereby, it is explained the Model Code 2010 approach to take into account the influence of prestressing on punching shear strength at LoA II and III (typical LoA to be used for structures where punching shear strength is governing). To do so, Model Code 2010 approach for slabs without prestress will first be explained. On that basis, the modifications to be considered for prestressed slabs will be detailed.

In a general manner MC2010 proposes to calculate the punching strength of members without transverse reinforcement as detailed in Equation (7):

$V_{E}-V_{p, M C} \leq V_{R, M C}=k_{\psi} \cdot b_{M C} \cdot d \cdot \sqrt{f_{c}}$

Where $V_{R, M C}$ is evaluated according to the CSCT failure criterion (refer to Eq. (2)), whose terms are evaluated through the following parameters:

$k_{\psi}=\frac{1}{1.5+0.9 \cdot \psi \cdot d \cdot k_{d g}} \leq 0.6$

With $k_{d g}$ defined in Eq. (3). The vertical component of the tendons $V_{P, M C}$ is calculated at $0.5 d$ from the border of the column as well as for the control perimeter $b_{M C}$ (see Figure 4). The rotation at failure ( $\psi$, refer to Eq. (8)) can be evaluated by using the Levels-of-Approximation approach. 


\section{Non prestressed slabs}

\section{Level of approximation II}

If the slab is subjected to vertical forces as shown in Figure 5a, the expression of the rotation can be given by Eq. (9):

$\psi=1.5 \frac{r_{s}}{d} \frac{f_{y}}{E_{s}}\left(\frac{m_{s}}{m_{R}}\right)^{3 / 2}$

where $r_{s}$ refers to the distance from the axis of the column to the line of contra-flexure of bending moments and is to be evaluated in the $x$ and $y$ directions. For LoA II and for regular slabs, it can be assumed that the zero moment line is located in the directions $x$ and $y$ at about $r_{s x}=0.22 \ell_{x}$ and $r_{s y}=0.22 \ell_{y}$ respectively (where $\ell_{x}$ and $\ell_{y}$ refer to the span lengths at the $x$ and $y$ directions respectively, Figure 5a). By using the values of $r_{s x}$ and $r_{s y}$ it is possible to determine the width $b_{s}$ of the support strip (Figure 5b), on which the moments acting near the supported region $\left(m_{s, x}\right.$ and $\left.m_{s, y}\right)$ have to be evaluated:

$b_{s}=1.5 \sqrt{r_{s x} \cdot r_{s y}}$

For inner columns without unbalanced moments (case that will later be compared to test results) and at LoA II, $m_{s}$ can be estimated as equal to $V / 8$. With respect to term $m_{R}$, it refers to the unitary bending strength (bending strength per unit length), which can be calculated assuming reinforcement yielding at failure.

\section{Level of approximation III}

The expression of the rotation given by Eq. (9) can be used by replacing factor 1.5 by 1.2 if the value of $r_{s x}$ and $r_{s y}$ are obtained from an elastic (uncracked) finite element analysis and the strip moments $\left(m_{s, x}\right.$ and $\left.m_{s, y}\right)$ are calculated as a function of the distribution of the acting moments on the support strip $\left(b_{s}\right)$. This can be performed by integration along the width of 
the support strip and at the border of the supported area (Figure 5c) of the acting moments due to external loads $\left(m_{V}\right)$ :

$m_{s x}=\frac{1}{b_{s}} \int_{-b_{s} / 2}^{+b_{s} / 2} m_{V, x} d y$ and $m_{s y}=\frac{1}{b_{s}} \int_{-b_{s} / 2}^{+b_{s} / 2} m_{V, y} d x$

\section{Prestressed slabs}

\section{Level of approximation II}

In presence of prestressing (Figure 6a), the rotation can be calculated according to Eq. (12):

$\psi=1.5 \frac{r_{s}}{d} \frac{f_{y}}{E_{s}}\left(\frac{m_{s}-m_{P}}{m_{R}-m_{P}}\right)^{3 / 2}$

This equation incorporates the influence of the decompression moment $\left(m_{p}\right)$, which can be calculated as (refer to Figure 7):

$m_{P}=n \cdot\left(\frac{h^{2}}{12(d-h / 2)}+e\right) \approx n \cdot\left(\frac{h}{2}-\frac{d}{3}+e\right)$

where $n$ is the normal force per unit length, $h$ the height of the slab, $d$ the effective depth and $e$ the eccentricity of the normal force from the centre of gravity of the section. It can be noted that this term effectively accounts for the influence of the in-plane forces $(n)$ and of its resulting bending moments (accounted by means of the prestressing eccentricity, $e$ ). As sign convention, the decompression moment is considered positive when it leads to compressive stresses on the top side of the slab (usual cases).

At LoA II, the rest of the parameters of Eq. (12) can be calculated in the same manner as for the case without prestressing. With respect to term $m_{R}$, it can be calculated assuming that both ordinary and prestressed reinforcement yield at failure. 


\section{Level of approximation III}

The rotation can be estimated (in an analogous manner as for non prestressed slabs) by replacing coefficient 1.5 of Eq. (12) by 1.2 if:

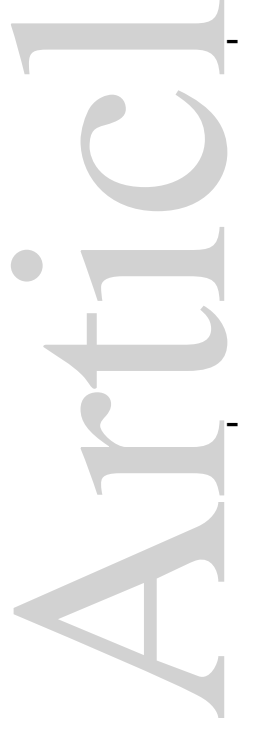

Distances $r_{s x}$ and $r_{s y}$ are calculated according to an elastic (uncracked) analysis of the slab performed accounting for all actions including prestressing (refer to $m_{V+P}$ in Figure $6 \mathrm{~b}$ ). It can be noted that for calculation of these parameters, the influence of prestressing is relatively limited and can in many cases be neglected.

The strip moments $\left(m_{s x}\right.$ and $\left.m_{s y}\right)$ are calculated by integration of the moments acting at the support strip. This integrations has to account for all actions except prestressing (refer to $m_{V}$ Figure $6 \mathrm{c}$ ) as prestressing effects are already considered on term $m_{P}$.

\section{COMPARISON OF TEST RESULTS WITH DESIGN CODES}

A large number of tests are available in the scientific literature dealing with slabs subjected to in-plane forces or prestressed [5, 7-10, 15-19,21,22]. In this section, 65 tests are compared to code predictions from Eurocode 2, ACI 318-11 and MC2010 in order to investigate on the suitability of each code. In the following, the strength predicted by the codes $\left(V_{\text {code }}\right)$ will be compared to the maximum load of the tests $\left(V_{R}\right)$ accounting for the inclined component of prestressing as previously explained:

$V_{R}=V_{E}$ for ACI 318-11 (since $V_{P, \mathrm{ACI}}$ is accounted for in the term of the punching shear strength, refer to Eq. (6))

$V_{R}=V_{E}-V_{P, E C}$ for Eurocode 2

$V_{R}=V_{E}-V_{P, M C}$ for MC2010

The detailed results are shown in Table 1 and Figure 8. With respect to the influence of the different phenomena induced by prestressing, the following observation can be done: 


\section{Influence of the vertical component of the tendons}

Figure 8a shows the ratio between the maximum load of the test and the strength predicted by the codes as a function of the normalized vertical component of the tendons $\left(V_{p} / V_{R}\right)$ calculated according to Figure 4a. ACI 318-11 and MC2010 provide a calculation of the vertical component along the control perimeter located at $0.5 \mathrm{~d}$ from the border of the column, whereas Eurocode 2 provides this value at $2 d$ from the border of the column. At this latter distance, more tendons are considered in the calculations and the inclination of the tendons can be significantly larger than at $0.5 d$. According to test results, Eurocode 2 control perimeter seems to overestimate the vertical component of the tendons particularly for larger values of $V_{p} / V_{R}$ (leading thus to unsafe results). The control perimeter located at $0.5 d$ seems to give better (trend-free) predictions, particularly for MC2010.

\section{Influence of in-plane stresses}

Figure $8 \mathrm{~b}$ shows the ratio between the maximum load of the test and the strength provided by the code predictions as a function of a normalized in-plane stress $\left(\sigma_{p} / f_{c}\right)$. All the investigated codes take into account the influence of the in-plane stress due to prestress on the punching shear strength. The code providing best predictions is MC2010, particularly at LoA III, where no visible trends are observed. In fact, a test performed by Regan [19] is subjected to a tensile stress $\left(\sigma_{p} / f_{c}=-0.12\right.$, left hand-side of the diagrams). While ACI 318-11 and Eurocode 2 do not estimate properly the strength for this test, the prediction of MC2010 at LoA III gives an accurate result, showing that using the decompression moment method provides consistent estimates of the punching strength.

\section{Influence of bending moments}

Figure 8c shows the influence of the bending moments (due to prestressing eccentricity). It can be noted that both ACI 318-11 and Eurocode 2 significantly increase their scatter on the 
strength predictions for increasing values of the normalized eccentricity $(e / d)$. On the contrary, MC2010 shows a trend-free behaviour, with limited scatter over the whole investigated range.

\section{CONCLUSIONS}

The present paper investigates the punching shear strength of prestressed slabs and compares several design codes predictions. The main conclusions of the paper are summarized below:

1. Punching shear strength is in general positively influenced by the presence of prestressing. The inclined component (force) of the tendons intersected by the punching failure surface reduces the shear force carried by concrete. Prestressing also induces both in-plane normal forces (compression) and bending moments (opposite to those of external actions) that increase the stiffness of the members, thus reducing crack widths and increasing punching shear strength.

2. Tendon inclination near the supported area is an effective manner to increase punching shear strength. However, only tendons close to the supported area (at a distance lower or equal than $0.5 d$ from the border of the column) are to be considered.

3. Using the decompression moment as a parameter to account for the influence of prestressing in flat slabs is an efficient manner to account both for the in-plane forces and bending moments originated by prestressing.

4. Most empirical design models, however, neglect the influence of bending moments due to prestressing. This leads to inaccurate results when compared to test results.

5. ACI 318-11 code provides, on average, safe results with a quite large scatter. Eurocode 2 provides better results on average than ACI, but with still large scatter of results and may lead potentially to fairly unsafe predictions of the punching shear 
strength. This is partly motivated by the choice of the perimeter at $2 d$, which seems to overestimate the contribution of inclined tendons.

6. The best predictions are obtained with Model Code 2010. Unlike the other investigated codes, Model Code 2010 is the only one that seems to take into account all effects of prestressing (normal in-plane force, tendons eccentricity and tendons inclination). Consequently the results are more accurate and less scattered. Furthermore, this approach seems not to lead to any tendencies as a function of the main physical parameters. Both Level-of-Approximations II and III proposed by the code lead to good estimates, although Level-of-Approximation III provides better results on average and a lower scatter. This latter level requires performing a linear analysis of the moment field of the slab, which is particularly suitable for highly unsymmetrical geometries as prestressed slab bridges. 


\section{NOTATIONS}

The following symbols are used in this paper:

$b_{0} \quad$ control perimeter

$b_{s} \quad$ length of moment integration

c column size (if squared)

d effective depth

$d_{v} \quad$ effective depth

$d_{g} \quad$ maximum aggregate diameter size

e eccentricity of the normal force from the center of gravity of the section

$f_{c} \quad$ average concrete compressive cylinder strength

h depth of the slab

$k_{d g} \quad$ coefficient depending on the aggregate size

$k_{\psi} \quad$ coefficient depending on the rotation

$m_{P} \quad$ average decompression moment over the width $b_{s}$ per unit length

$m_{R} \quad$ resisting moment per unit length

$m_{s} \quad$ average moment over the width $b_{s}$ per unit length

$m_{V}$ moment due to actions other than prestressing

$m_{V+P} \quad$ moment due to all actions (including prestressing)

$n \quad$ normal force per unit length

column radius

$r_{s} \quad$ radius from the center of the column the the zero moment line

x $\quad \mathrm{x}$ direction

$y \quad$ y direction

$\ell \quad$ span of the slab

$V \quad$ shear force 
$V_{R} \quad$ punching shear strength

$V_{\text {code }} \quad$ punching shear strength provided by a code

$V_{p} \quad$ vertical component of the tendons force on a specified section

$V_{E} \quad$ acting shear force

$\beta_{p} \quad$ coefficient depending on the type of column for ACI approach

$\phi \quad$ column diameter (if circular)

$\sigma_{P} \quad$ normal compressive stress

$\psi \quad$ rotation of the slab outside the column region

$\psi_{R} \quad$ rotation of the slab at failure

ACI related to ACI $318(2011)$

EC related to Eurocode 2 (2004)

- MC related to Model Code 2010 


\section{REFERENCES}

[1] ACI Building Code Requirements for Structural Concrete, ACI 318-11, American Concrete Institute, ACI Committee 318, 503 p., Detroit, 2011.

[2] Eurocode Eurocode 2: Design of concrete structures - Part 1-1: General rules and rules for buildings, European Committee for Standardization (CEN), Brussels, December, 2004.

[3] Fernández Ruiz, M., Mirzaei Y., Muttoni, A., Post-Punching Behavior of Flat Slabs, ACI Structural Journal, accepted for publication

[4] FIB fib Model Code 2010 Final Draft, 653 p., Lausanne, Suisse, March, 2012.

[5] Hassanzadeh G. Betongplattor pa pelare Dimensioneringsmetoder för plattor med icke vidhäftande spännarmering, Institutionen för Byggkonstruktion, Kungl. Tekniska Högskolan, Bulletin 43, 162 p., Stockholm, Sweden, 1998.

[6] Kaminetzky D. Design and Construction Failures - Lessons from Forensic Investigations, McGraw-Hill., New York, 600 p., 1991.

[7] Kordina K., Nölting D. Tragfähigkeit durchstanzgefährdeter Stahlbetonplatten, Deutscher Ausschuss für Stahlbeton, 371, 167 p., Berlin, Germany, 1986.

[8] Lúcio, V. J. G., Appleton, J. A. S., and Almeida, J. F. Ultimate limit state of punching in the (fib) FIP recommendations for the design of post-tensioned slabs and foundations. Structural Concrete, Vol. 1, no. 3, pp.143-149, 2000

[9] Melges J. L. P. Analise experimental da punçao em lajes de concreto armado e protendido, Escola de Engenharia de São Carlos, Universidade de São Paulo, 414, São Carlos, Brazil, 2001.

[10] Moreillon L. Poinçonnement de dalles minces en béton à hautes performances, Ecole d'ingénieurs et d'architectes de Fribourg, 83 p., Suisse, 2008. 
[11] Muttoni A. Punching shear strength of reinforced concrete slabs without transverse reinforcement, ACI Structural Journal, V. 105, N 4, pp. 440-450, USA, July-August, 2008

[12] Muttoni A. Sécurité structurale des parkings couverts, Documentation SIA, A. Muttoni, Editor, 105 p., Zürich, Switzerland, June, 2008.

[13] Muttoni A., Fernández Ruiz M. Levels-of-approximation approach in codes of practice, Structural Engineering International, 2012 Vol. 2, pp. 190-194, Zurich, Switzerland, May, 2012.

[14] Muttoni A., Fernández Ruiz M. The levels-of-approximation approach in MC 2010: application to punching shear provisions, Structural Concrete, Vol. 13, pp. 32-41, 2012.

[15] Nylander H., Kinnunen S., Ingvarsson H. Genomstansning av pelarunderstödd plattbro av betong med spänd och ospänd armering, Test Report KTH, nr. 123, 56 p., Stockholm, Sweden, 1977.

[16] Pralong J., Brändli W., Thürlimann B. Durchstanzersuche an Stahlbeton und Spannbetonplatten, Birkhäuser Verlag, Institut für Baustatik und Konstruktion ETH Zürich, Nr. 7305-3, Switzerland, 1979.

[17] Ramos A.P. Punçoamento em lajes fungiformes pré-esforçadas, Universidade Tecnica de Lisboa - Instituto Superior Tecnico, 292 p., Lisboa, Portugal, 2003.

[18] Ramos, A. P., Lúcio, V e Regan, P.E.. Punching of flat slabs with in-plane force, Engineering Structures, Volume 33, Issue 3 , March, 2011.

[19] Regan P. E. Punching Shear in Prestressed Concrete Slab Bridges, Engineering Structures Research group, Polytechnic of Central London, 230 p., London, UK, January, 1983. 
[20] SETO, Design of Post-Tensioned Slabs and Foundations, FIP Recommendations, London, 1999, 44 pp.

[21] Shehata I. A. E. M. Theory of punching in RC slabs, Ph.D Thesis, Polytechnic of Central London, UK, 1985.

[22] Silva R. J. C., Regan P. E., Melo G.S.S.A, Punching resistances of unbonded posttensioned slabs by decompression methods, Thomas Telford and fib, Structural Concrete, No 1, 21 p., 2005.

[23] Silva R. J. C., Regan P. E., Melo G.S.S.A, Punching of Post-Tensioned Slabs-Tests and Codes, American Concrete Institute, Vol. 104, No. 2, pp. 123-132, 2007

\section{Corresponding author:}

Miguel Fernández Ruiz

Ecole Polytechnique Fédérale de Lausanne - IBETON

Station 18 Lausanne CH-1024

Switzerland

Email: miguel.fernandezruiz@epfl.ch 


\section{Figures:}

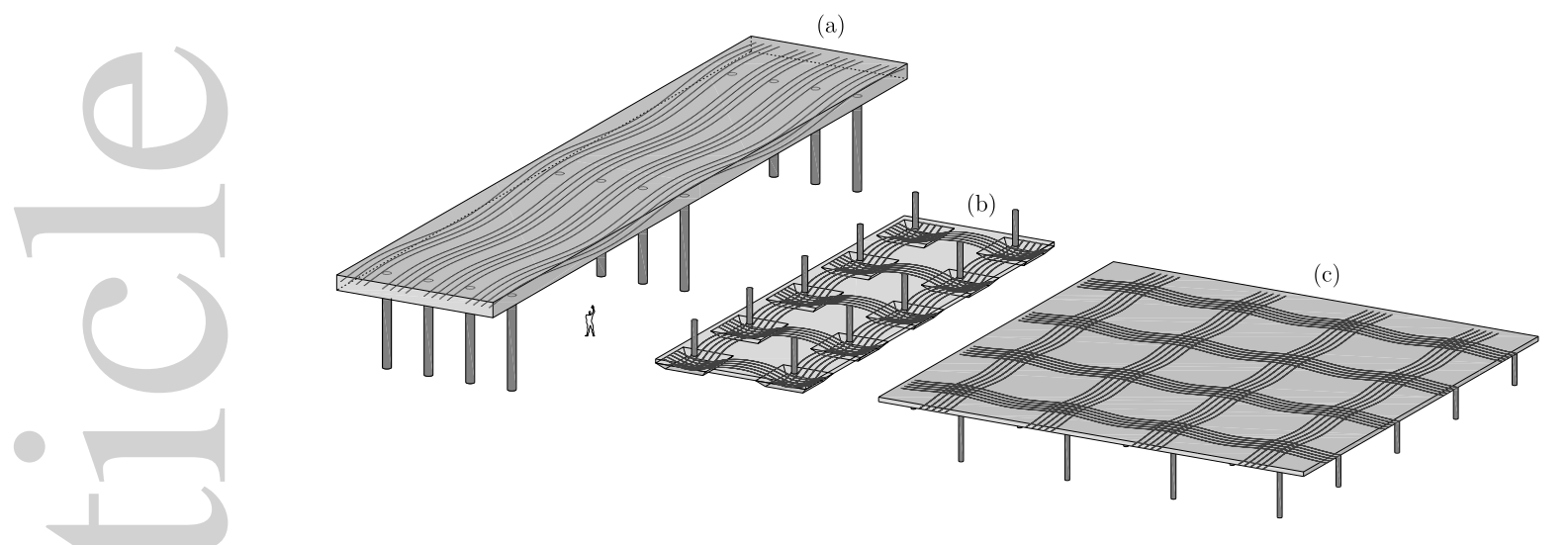

Figure 1: $\quad$ Examples of prestressed structures: (a) slab bridge; (b) footings; and (c) flat slab

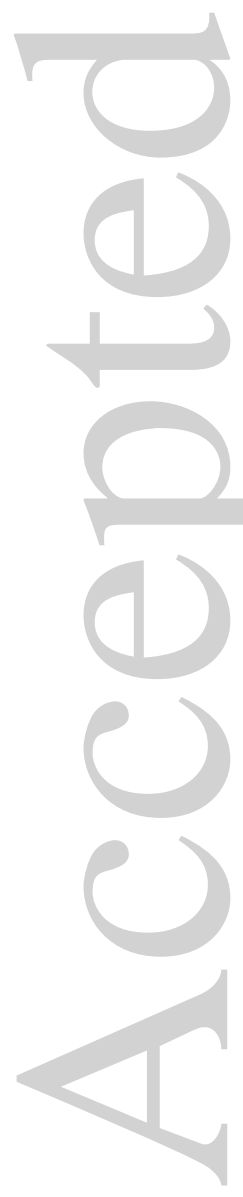


(a)
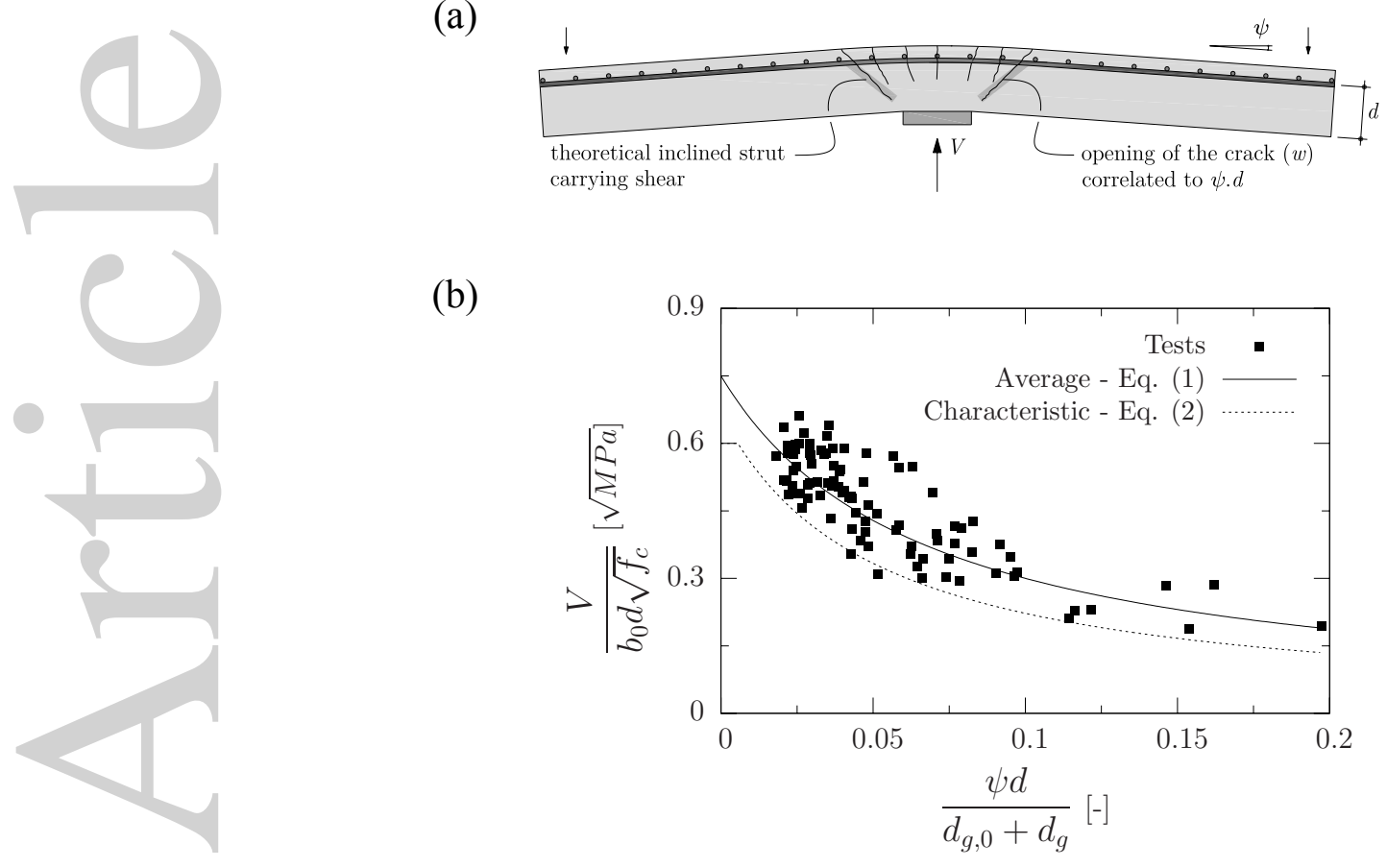

(b)

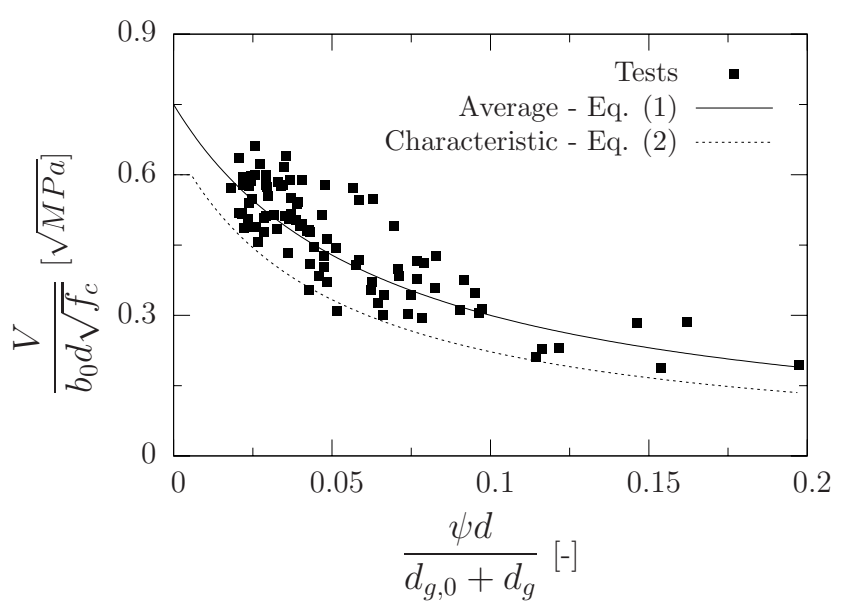

(c)

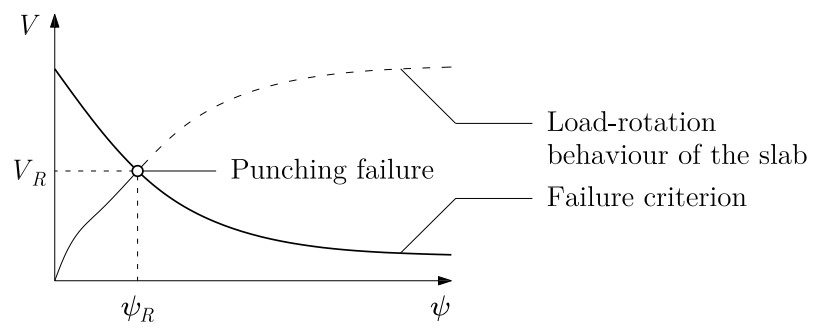

Figure 2: The Critical Shear Crack Theory: (a) critical shear crack developing through the compression strut carrying shear; (b) failure criteria and comparison to 99 test results (data according to [11]); and (c) calculation of the strength and deformation capacity 
(a)

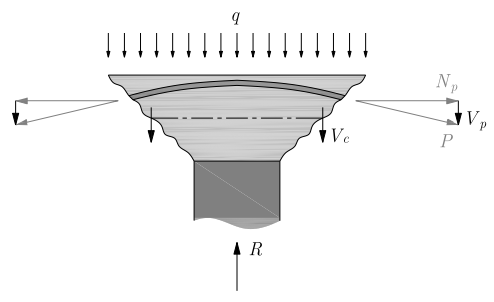

(b)
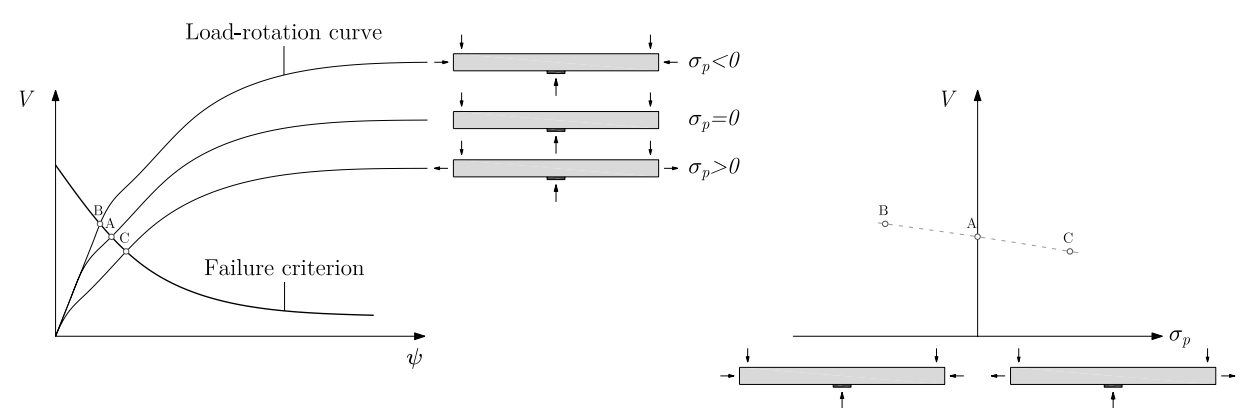

(c)
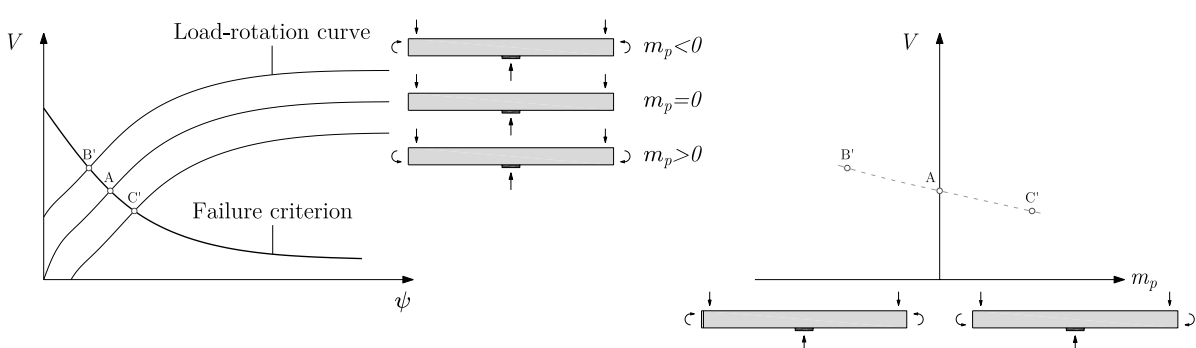

Figure 3: Phenomena influencing punching shear strength of prestressed slabs: (a) reduction of shear force due to the inclined component (force) of tendons; (b) influence of an inplane force; and (c) influence of a bending moment

(a)

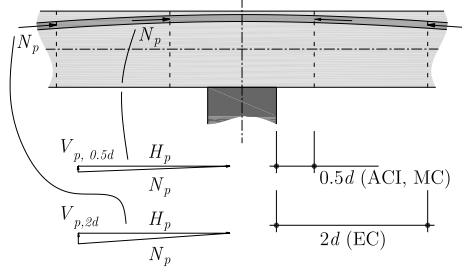

(b)

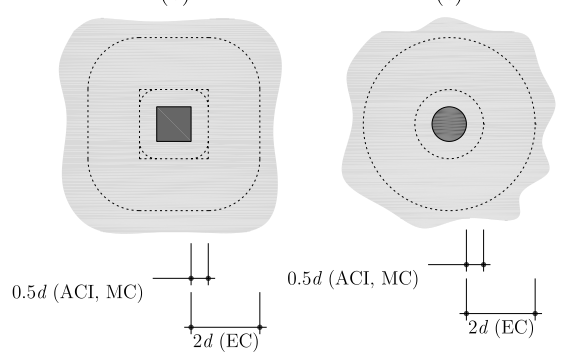

Figure 4: Parameters of design codes: (a) vertical component of the tendons according to ACI 318, Eurocode 2 and Model; (b) square columns; and (c) circular columns 

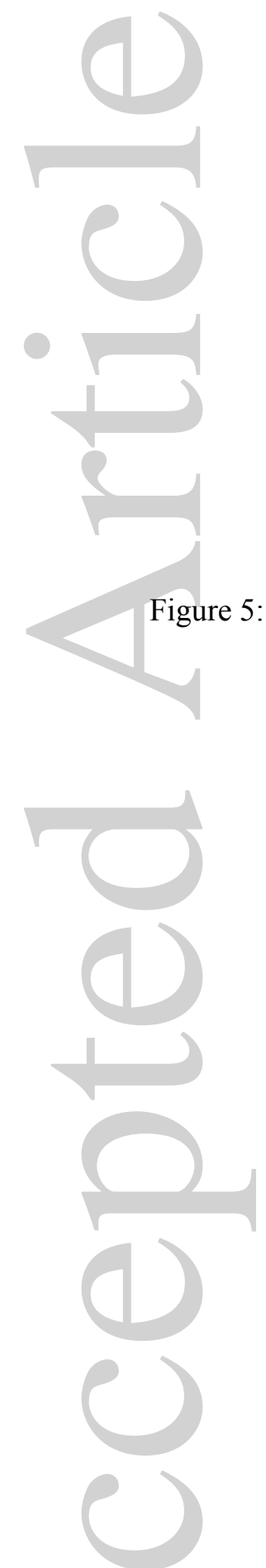

Figure 6:

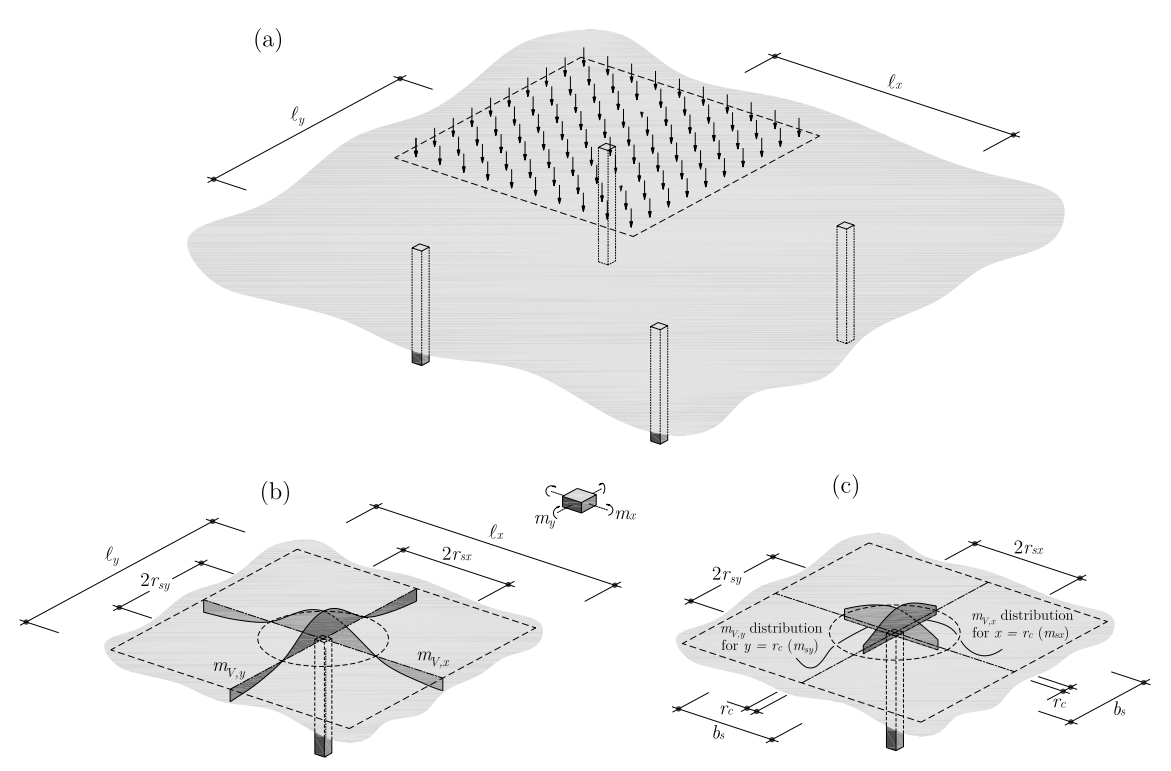

Non-prestressed flat slab: (a) geometry; (b) moment distribution $\left(m_{V, x}, m_{V, y}\right)$ in each direction over the support; and (c) moment distribution $\left(m_{V, x}, m_{V, y}\right)$ at edge of supported area over a length $b_{s}$

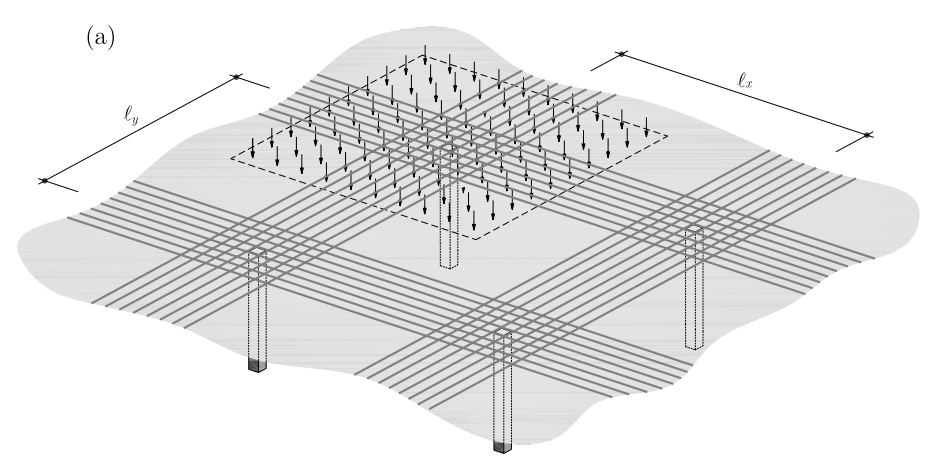

(b)

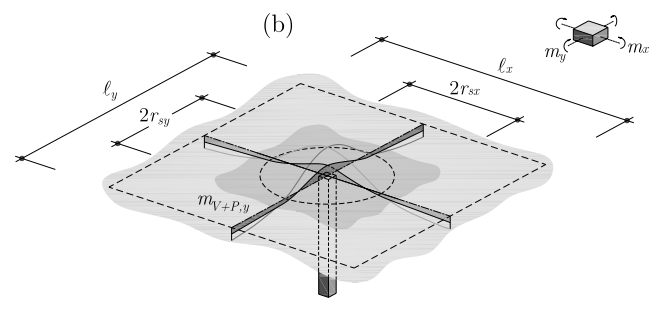

(c)

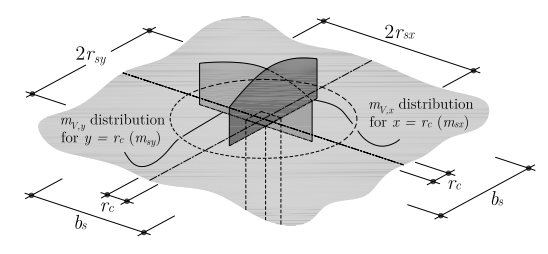

Prestressed flat slab: (a) geometry; (b) total moment distribution $\left(m_{V+P, x}, m_{V+P, y}\right)$ in each direction over the support; and (c) moment distribution due to actions excluding prestressing $\left(m_{V, x}, m_{V, y}\right)$ at edge of supported area over a length $b_{s}$ 

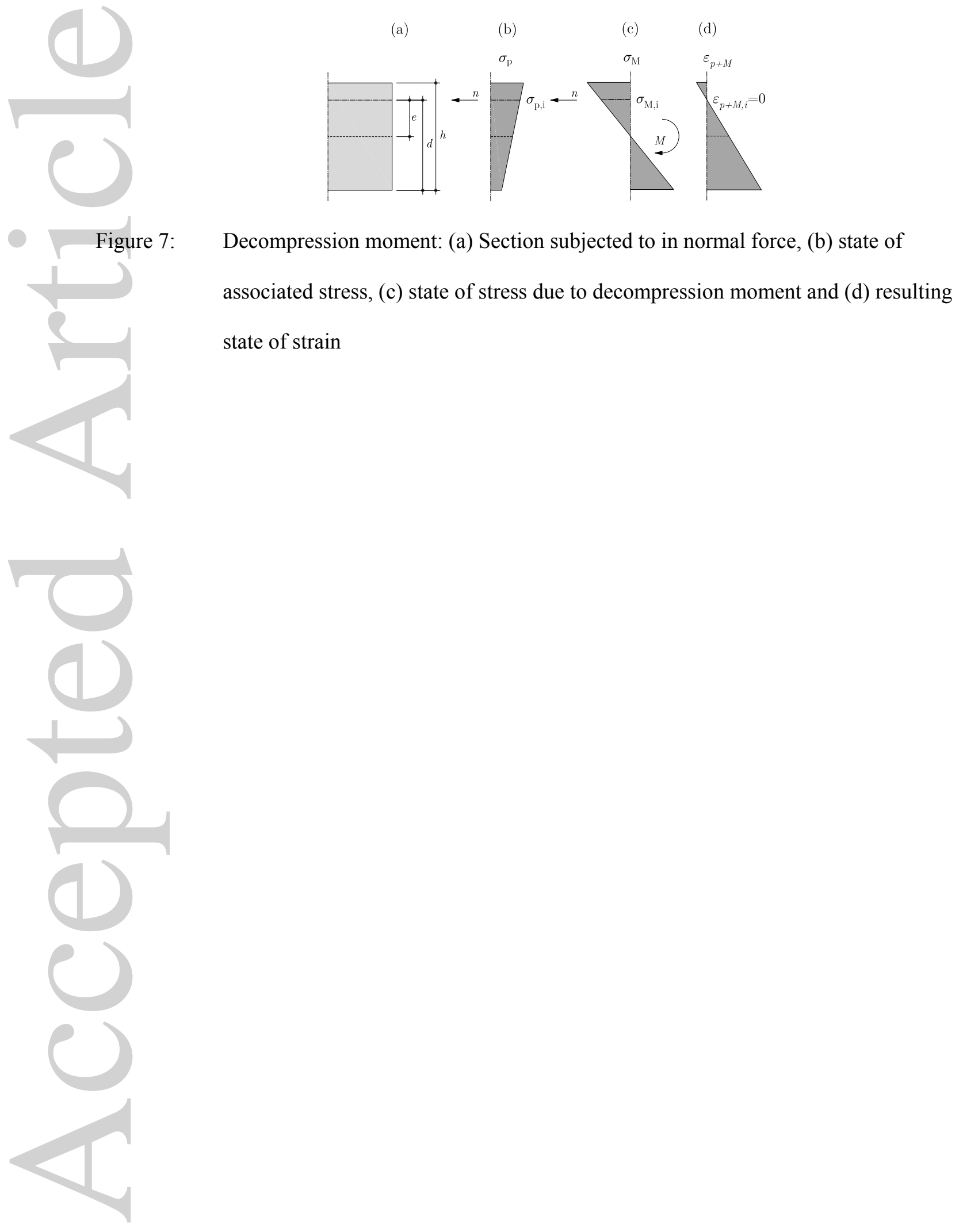

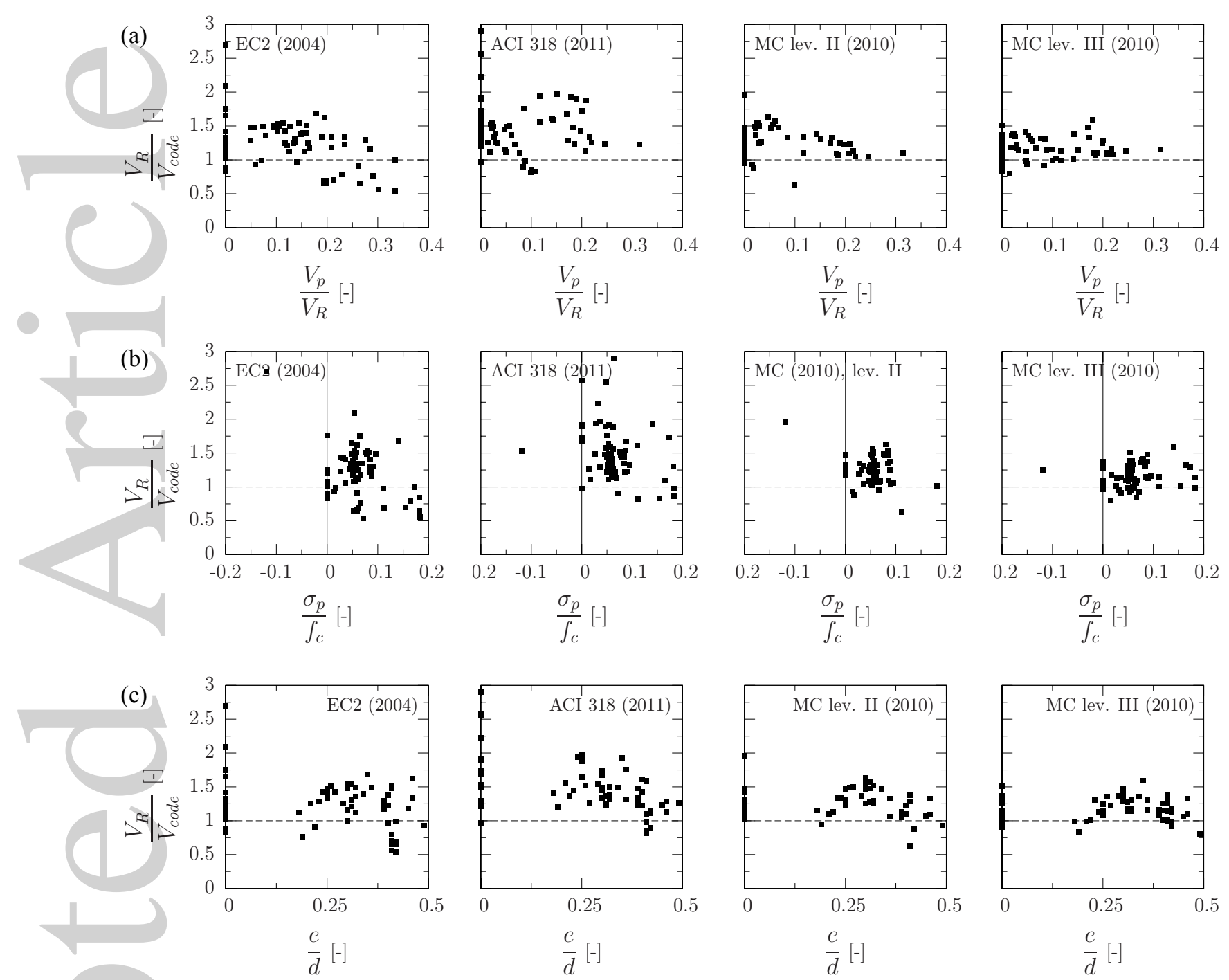

Figure 8: Prediction of the punching strength for tests taken from the literature as a function of:

(a) the ratio between the vertical component of the tendons and the strength of the test;

(b) the introduced in-plane compression stress; and (c) the applied moments due to tendon or i-plane force eccentricity 
Table 1: Comparison of test results and investigated codes

\begin{tabular}{|c|c|c|c|c|c|c|c|c|c|c|c|c|}
\hline Author & Slab & $\begin{array}{l}V_{E} \\
{[\mathrm{kN}]}\end{array}$ & $\begin{array}{l}V_{p, 0.5 d} \\
{[\mathrm{kN}]}\end{array}$ & $\begin{array}{l}V_{p, 2 d} \\
{[\mathrm{kN}}\end{array}$ & $\begin{array}{c}d \\
{[\mathrm{~mm}]}\end{array}$ & $\begin{array}{c}f_{c} \\
{[\mathrm{MPa}]}\end{array}$ & $\begin{array}{c}\sigma_{p} \\
{[\mathrm{MPa}]}\end{array}$ & $\begin{array}{c}c \text { or } \phi^{* * *} \\
{[\mathrm{~mm}]}\end{array}$ & $\begin{array}{c}V_{R} / V_{R, E C} \\
{[-]}\end{array}$ & $\begin{array}{c}V_{R} / V_{R, A C I} \\
{[-]}\end{array}$ & $\begin{array}{c}V_{R} / V_{R, M C, I I} \\
{[-]}\end{array}$ & $\begin{array}{c}V_{R} / V_{R, M C, I I I} \\
{[-]}\end{array}$ \\
\hline Kinnunen and al. & P11 & 709 & 70.3 & 141 & 205 & 35.1 & 3.93 & $240(\phi)$ & 0.69 & 0.82 & 0.63 & 1.10 \\
\hline Kinnunen and al. & $\mathrm{P} 12$ & 796 & 70.4 & 211 & 204 & 28.8 & 5.25 & $240(\phi)$ & 0.65 & 0.98 & $(*)$ & 1.11 \\
\hline Kinnunen and al. & $\mathrm{P} 13$ & 920 & 70.4 & 211 & 204 & 31.9 & 5.25 & $240(\phi)$ & 0.79 & 1.10 & $(*)$ & 1.27 \\
\hline Kinnunen and al. & $\mathrm{P} 14$ & 701 & 70.4 & 211 & 204 & 28.7 & 5.25 & $240(\phi)$ & 0.56 & 0.86 & $(*)$ & 0.96 \\
\hline Kinnunen and al. & P16 & 659 & 70.3 & 141 & 205 & 25.5 & 3.93 & $240(\phi)$ & 0.70 & 0.83 & $(*)$ & 0.98 \\
\hline Pralong and al. & P5 & 568 & 0 & 0 & 154 & 27.1 & 2.65 & $300(\phi)$ & 1.08 & 1.71 & 1.18 & 1.02 \\
\hline Pralong and al. & P7 & 767 & 106 & 160 & 160 & 31.2 & 2.60 & $300(\phi)$ & 1.18 & 1.23 & 1.07 & 1.01 \\
\hline Pralong and al. & P8 & 683 & 106 & 160 & 158 & 29.6 & 3.00 & $300(\phi)$ & 1.34 & 1.13 & 1.09 & 1.03 \\
\hline Pralong and al. & P9 & 820 & 106 & 160 & 158 & 35 & 2.90 & $300(\phi)$ & 1.62 & 1.29 & 1.33 & 1.24 \\
\hline Shehata & SP1 & 988 & 177 & 177 & 130 & 36.5 & 5.14 & $150(c)$ & 1.68 & 1.93 & $(*)$ & 1.59 \\
\hline Shehata & SP2 & 624 & 88 & 88 & 129 & 46.4 & 5.14 & $150(c)$ & 0.97 & 1.61 & $(*)$ & 1.01 \\
\hline Shehata & SP3 & 416 & 0 & 0 & 151 & 41.0 & 0 & $150(c)$ & 0.83 & 1.92 & 1.18 & 1.09 \\
\hline Shehata & SP4 & 884 & 177 & 296 & 129 & 41.7 & 7.20 & $150(c)$ & 1.00 & 1.73 & $(*)$ & 1.27 \\
\hline Shehata & SP5 & 780 & 133 & 222 & 129 & 40.9 & 3.60 & $150(c)$ & 1.16 & 1.67 & 1.25 & 1.33 \\
\hline Regan & DT1 & 780 & 0 & 0 & 197 & 43.6 & 0 & $150(c)$ & 1.02 & 1.73 & 1.28 & 1.35 \\
\hline Regan & DT2 & 832 & 40.2 & 161 & 177 & 40.1 & 8.90 & $150(c)$ & 0.69 & 1.15 & $(*)$ & 1.12 \\
\hline Regan & DT3 & 962 & 80.4 & 322 & 177 & 43.2 & 8.90 & $300(c)$ & 0.54 & 0.90 & $(*)$ & 0.92 \\
\hline Regan & DT4 & 715 & 12.6 & 50.0 & 177 & 47.2 & 2.80 & $150(c)$ & 0.99 & 1.11 & 0.88 & 1.12 \\
\hline Regan & DT6 & 832 & 40.2 & 161 & 177 & 42.9 & 8.90 & $150(c)$ & 0.67 & 1.15 & $(*)$ & 0.98 \\
\hline Regan & DT8 & 676 & 9.90 & 39.6 & 184 & 45.6 & 2.20 & $150(c)$ & 0.93 & 1.26 & 0.93 & 1.17 \\
\hline Regan & DT9 & 806 & 40.2 & 161 & 177 & 45.0 & 8.90 & $150(c)$ & 0.65 & 1.11 & $(*)$ & 0.94 \\
\hline Regan & DT10 & 832 & 40.2 & 161 & 177 & 43.7 & 8.90 & $150(c)$ & 0.65 & 1.15 & $(*)$ & 0.98 \\
\hline Regan & BD1 & 293 & 0 & 0 & 101 & 42.2 & 7.65 & $100(c)$ & 0.84 & 1.30 & 1.02 & 1.14 \\
\hline Regan & BD2 & 268 & 0 & 0 & 101 & 39.2 & 0 & $100(c)$ & 1.76 & 1.92 & 1.48 & 1.30 \\
\hline Regan & BD5 & 208 & 0 & 0 & 101 & 33.1 & -3.95 & $100(c)$ & 2.70 & 1.53 & 1.96 & 1.25 \\
\hline Kordina and al. & V1 & 450 & 74.1 & 74.1 & 126 & 33.6 & 1.70 & $200(\phi)$ & 1.17 & 1.26 & 1.05 & 0.92 \\
\hline Kordina and al. & $\mathrm{V} 2$ & 525 & 71.9 & 71.9 & 126 & 36.0 & 1.66 & $200(\phi)$ & 1.26 & 1.48 & 1.09 & 0.98 \\
\hline Kordina and al. & $\mathrm{V} 3$ & 570 & 134 & 134 & 124 & 36.0 & 3.09 & $200(\phi)$ & 1.22 & 1.22 & 1.10 & 1.05 \\
\hline Kordina and al. & V6 & 375 & 0 & 0 & 118 & 30.4 & 1.77 & $200(\phi)$ & 1.33 & 1.49 & 1.23 & 0.99 \\
\hline Kordina and al. & V7 & 475 & 77.1 & 77.1 & 126 & 31.2 & 1.77 & $200(\phi)$ & 1.25 & 1.34 & 1.13 & 0.99 \\
\hline Kordina and al. & V8 & 518 & 77.1 & 77.1 & 126 & 35.2 & 1.77 & $200(\phi)$ & 1.38 & 1.43 & 1.22 & 1.07 \\
\hline Hassanzadeh & A1 & 668 & 75 & 184 & 151 & 31.0 & 2.79 & $250(\phi)$ & 1.30 & 1.23 & 1.05 & 1.07 \\
\hline Hassanzadeh & $\mathrm{A} 2$ & 564 & 0 & 59.0 & 146 & 28.7 & 2.74 & $250(\phi)$ & 1.49 & 1.32 & 1.06 & 1.05 \\
\hline Hassanzadeh & $\mathrm{B} 1$ & 439 & 0 & 0 & 190 & 40.9 & 0 & $250(\phi)$ & 0.89 & 0.97 & 1.21 & 1.07 \\
\hline Hassanzadeh & $\mathrm{B} 2$ & 827 & 0 & 0 & 190 & 39.0 & 2.12 & $250(\phi)$ & 2.09 & 1.92 & 1.43 & 1.49 \\
\hline Hassanzadeh & B3 & 1113 & 74 & 178 & 190 & 38.6 & 2.21 & $250(\phi)$ & 1.51 & 1.59 & 1.38 & 1.40 \\
\hline Hassanzadeh & B4 & 952 & 0 & 52.6 & 190 & 40.5 & 1.99 & $250(\phi)$ & 1.48 & 1.58 & 1.29 & 1.25 \\
\hline
\end{tabular}




\begin{tabular}{|c|c|c|c|c|c|c|c|c|c|c|c|c|}
\hline Author & Slab & $\begin{array}{l}V_{R} \\
{[\mathrm{kN}]}\end{array}$ & $\begin{array}{l}V_{p, 0.5 d} \\
{[\mathrm{kN}]}\end{array}$ & $\begin{array}{l}V_{p, 2 d} \\
{[\mathrm{kN}]}\end{array}$ & $\begin{array}{c}d \\
{[\mathrm{~mm}]}\end{array}$ & $\begin{array}{c}f_{c} \\
{[\mathrm{MPa}]}\end{array}$ & $\begin{array}{c}\sigma_{p} \\
{[\mathrm{MPa}]}\end{array}$ & $\begin{array}{c}c \text { or } \phi^{* * *} \\
{[\mathrm{~mm}]}\end{array}$ & $\begin{array}{l}V_{R} / V_{E C} \\
{[-]}\end{array}$ & $\begin{array}{l}V_{R} / V_{A C I} \\
{[-]}\end{array}$ & $\begin{array}{l}V_{R} / V_{M C, I I} \\
{[-]}\end{array}$ & $\begin{array}{l}V_{R} / V_{M C, I I I} \\
{[-]}\end{array}$ \\
\hline Melges & M1 & 441 & 0 & 0 & 127 & 26.6 & 0 & $180(c)$ & 1.20 & 1.89 & 1.32 & 1.13 \\
\hline Melges & M4 & 772 & 66 & 99 & 132 & 51.9 & 2.58 & $180(c)$ & 1.49 & 1.76 & 1.30 & 1.24 \\
\hline Moreillon & B1-01 & 262 & 0 & 0 & 90 & 90 & 0 & $120(\phi)$ & 1.25 & 2.57 & 1.47 & 0.96 \\
\hline Moreillon & B1-02 & 294 & 0 & 0 & 81 & 90 & 2.88 & $120(\phi)$ & 1.42 & 2.23 & 1.25 & 0.95 \\
\hline Moreillon & B1-03 & 330 & 0 & 0 & 76 & 90 & 4.33 & $120(\phi)$ & 1.65 & 2.55 & 1.23 & 0.99 \\
\hline Moreillon & B1-04 & 376 & 0 & 0 & 76 & 90 & 5.77 & $120(\phi)$ & 1.75 & 2.90 & 1.32 & 1.10 \\
\hline Ramos & AR2 & 258 & 0 & 0 & 80 & 39.1 & 0 & $200(c)$ & 1.24 & 1.68 & 1.22 & 0.99 \\
\hline Ramos & AR3 & 270 & 0 & 0 & 80 & 37.5 & 1.00 & $200(c)$ & 1.23 & 1.49 & 1.19 & 1.02 \\
\hline Ramos & AR4 & 252 & 0 & 0 & 80 & 43.1 & 1.55 & $200(c)$ & 1.06 & 1.29 & 1.05 & 0.91 \\
\hline Ramos & AR5 & 251 & 0 & 0 & 80 & 35.7 & 2.00 & $200(c)$ & 1.09 & 1.21 & 1.07 & 0.95 \\
\hline Ramos & AR6 & 250 & 0 & 0 & 80 & 37.0 & 1.95 & $200(c)$ & 1.08 & 1.21 & 1.03 & 0.92 \\
\hline Ramos & AR7 & 288 & 0 & 0 & 80 & 43.9 & 2.75 & $200(c)$ & 1.13 & 1.26 & 1.10 & 1.01 \\
\hline Ramos & AR8 & 380 & 72.2 & 72.2 & 78 & 41.6 & 1.95 & $200(c)$ & 1.34 & 1.90 & 1.25 & 1.07 \\
\hline Ramos & AR10 & 371 & 56.4 & 56.4 & 78 & 41.4 & 1.51 & $200(c)$ & 1.40 & 1.97 & 1.31 & 1.10 \\
\hline Ramos & AR11 & 342 & 40.1 & 40.1 & 78 & 38.0 & 1.04 & $200(c)$ & 1.43 & 1.94 & 1.34 & 1.09 \\
\hline Ramos & AR12 & 280 & 32.8 & 32.8 & 75 & 31.3 & 1.95 & $200(c)$ & 1.25 & 1.56 & 1.10 & 0.96 \\
\hline Ramos & AR13 & 261 & 0 & 68.2 & 76 & 32.5 & 1.94 & $200(c)$ & 0.91 & 1.37 & 1.13 & 0.98 \\
\hline Ramos & AR14 & 208 & 0 & 60.5 & 76 & 28.2 & 1.87 & $200(c)$ & 0.76 & 1.20 & 0.95 & 0.82 \\
\hline Ramos & AR15 & 262 & 0 & 32.7 & 76 & 31.7 & 1.93 & $200(c)$ & 1.12 & 1.41 & 1.15 & 1.00 \\
\hline Ramos & AR16 & 351 & 73.4 & 73.4 & 77 & 30.6 & 1.92 & $200(c)$ & 1.34 & 1.88 & 1.23 & 1.05 \\
\hline Silva & A1 & 380 & 8.20 & 50.8 & 109 & 37.8 & 3.31 & $100(c)$ & 1.25 & 1.54 & 1.37 & 1.29 \\
\hline Silva & A2 & 315 & 9.00 & 48.9 & 113 & 37.8 & 2.14 & $100(c)$ & 1.12 & 1.39 & 1.25 & 1.09 \\
\hline Silva & A3 & 353 & 0 & 17.4 & 109 & 37.8 & 3.16 & $100(c)$ & 1.29 & 1.45 & 1.34 & 1.23 \\
\hline Silva & A4 & 321 & 0 & 16.4 & 104 & 37.8 & 1.98 & $100(c)$ & 1.48 & 1.64 & 1.47 & 1.25 \\
\hline Silva & B1 & 582 & 30.5 & 92.5 & 114 & 40.1 & 3.39 & $200(c)$ & 1.40 & 1.49 & 1.47 & 1.30 \\
\hline Silva & B2 & 488 & 27.3 & 61.8 & 110 & 40.1 & 2.23 & $200(c)$ & 1.49 & 1.50 & 1.52 & 1.25 \\
\hline Silva & B3 & 520 & 11.5 & 48.7 & 108 & 40.1 & 3.12 & $200(c)$ & 1.48 & 1.47 & 1.47 & 1.32 \\
\hline Silva & B4 & 459 & 11.5 & 47.1 & 106 & 40.1 & 2.16 & $200(c)$ & 1.53 & 1.49 & 1.55 & 1.30 \\
\hline Silva & $\mathrm{C} 1$ & 720 & 33.9 & 104 & 111 & 41.6 & 3.33 & $300(c)$ & 1.54 & 1.45 & 1.63 & 1.36 \\
\hline Silva & $\mathrm{C} 2$ & 557 & 33.6 & 63.0 & 105 & 41.6 & 2.26 & $300(c)$ & 1.54 & 1.37 & 1.57 & 1.23 \\
\hline Silva & $\mathrm{C} 3$ & 637 & 16.8 & 61.6 & 106 & 41.6 & 3.48 & $300(c)$ & 1.51 & 1.34 & 1.54 & 1.29 \\
\hline Silva & $\mathrm{C} 4$ & 497 & 14.6 & 50.9 & 102 & 41.6 & 2.31 & $300(c)$ & 1.43 & 1.26 & 1.50 & 1.16 \\
\hline Silva & D1 & 497 & 9.7 & 46.9 & 111 & 44.1 & 3.34 & $200(c)$ & 1.51 & 1.52 & 1.49 & 1.30 \\
\hline Silva & $\mathrm{D} 2$ & 385 & 12.6 & 40.8 & 105 & 44.1 & 2.23 & $200(c)$ & 1.24 & 1.24 & 1.27 & 1.08 \\
\hline Silva & D3 & 395 & 0 & 31.3 & 106 & 44.1 & 2.27 & $200(c)$ & 1.36 & 1.32 & 1.30 & 1.08 \\
\hline Silva & D4 & 531 & 35.9 & 72.3 & 102 & 44.1 & 2.22 & $300(c)$ & 1.31 & 1.22 & 1.38 & 1.13 \\
\hline & & & & & & & & & EC & $\mathrm{ACI}$ & $\mathrm{MC}, \mathrm{II}$ & MC,III \\
\hline Mean & & & & & & & & & 1.23 & 1.48 & 1.26 & 1.16 \\
\hline $\mathrm{COV}$ & & & & & & & & & 0.30 & 0.26 & 0.17 & 0.14 \\
\hline $5 \%$ fractile & & & & & & & & & 0.65 & 0.90 & 0.93 & 0.92 \\
\hline
\end{tabular}


(*) decompression moment $m_{P}$ is larger than $m_{s}$. Calculation of the strength is thus not performed at this Level-of-Approximation

(**) $c$ refers to square columns, where $c$ is the side of the column and $\phi$ refers to circular columns, where $\phi$ is the column diameter
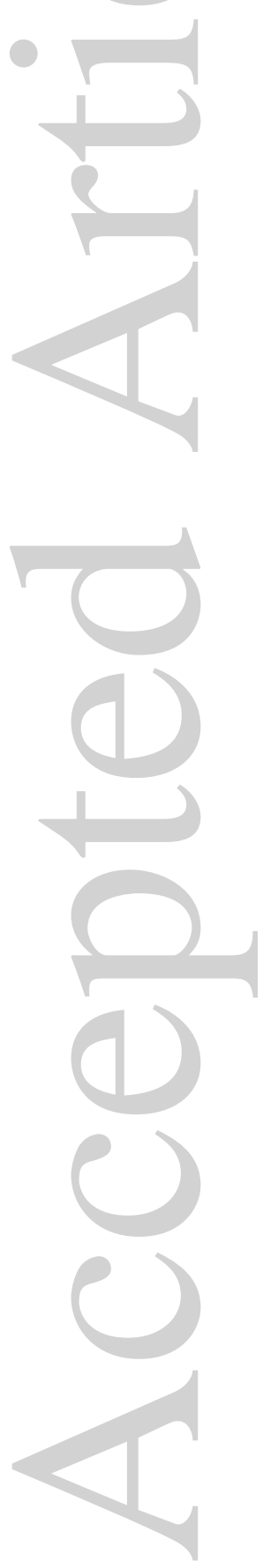